13. National Botanic Garden of Wales [El. resource] // https://botanicgarden.wales.

14. Singapore Botanic Gardens [El. resource] // https://sbg.org.sg.

15. The New York Botanical Garden [El. resource] // https://nybg.org.

16. Tegegn Argaw Opportunities of Botanical Garden in Environmental and Development Education to Support School Based Instruction in Ethiopia. Journal of Biology, Agriculture and Healthcare. 2015. Vol. 5, № 15. P. 92-109.
17. Tunnicliffe S.D. Talking about plants: Comments of primary school groups looking at plant exhibits in a botanical garden // Journal of Biological Education. 2001. 36 (1). P. 27-34.

18. Peter Wyse Jackson The developing role of botanic gardens in plant conservation: implementing the global strategy for plant conservation // Сады в наших сердцах: Коллективная монография по материалам 3й междунар. конф. «Жизнь в гармонии: ботанические сады и общество - диалог без границ». Тверь, Россия, 13-16 октября 2013 г. Тверь, 2013. С. 35-51.

\title{
PERMANENT AND TEMPORARY EXPOSITIONS OF SUCCULENTS IN THE BOTANICAL GARDEN OF PETER THE GREAT AS A WAY OF BIOLOGICAL AND ECOLOGICAL EDUCATION
}

(C) 2017

Kalugin Yuri Guryanovich, researcher

Musinova Larisa Petrovna, methodist of Cultural and Educational Center

V.L. Komarov Botanical Institute of Russian Academy of Sciences (Saint Petersburg, Russian Federation)

Abstract. The paper describes one of the ways of organizing educational activities in the expositions of the Peter the Great Botanical Garden in St. Petersburg. The authors study the problem of actualization of environmental knowledge among the population and preservation of biodiversity through leisure. The paper analyzes educational work in Russian botanical gardens and some foreign gardens at the present time. The authors introduce the term «complex garden» as a garden of broad educational opportunities. The paper describes a collection of plants of one of the oldest and largest botanical gardens in Russia. The authors demonstrate a variety of topics for study, detail the content of exhibitions and describe the ways of active and passive activity of visitors on the example of expositions of succulent plants. The paper provides a diagram of ecological and biological knowledge improvement.

Keywords: biodiversity; environmental education; biological and environmental education; education in botanic gardens; permanent expositions; collection formation principles; plant exhibitions; succulent plants; active and passive forms of education; «fields» for formation of knowledge.

УдК 378.02

Статья поступила в редакцию 19.09.2017

\section{МОДЕЛЬ ФОРМИРОВАНИЯ ЭКОЛОГИЧЕСКОЙ КУЛЬТУРЫ У СТУДЕНТОВ - БУДУЩИХ УЧИТЕЛЕЙ ИЗОБРАЗИТЕЛЬНОГО И ДЕКОРАТИВНО-ПРИКЛАДНОГО ИСКУССТВА} (C) 2017

Левина Светлана Викторовна, кандидат педагогических наук, доцент кафедры физики, математики и методики обучения

Самарский государственный социально-педагогический университет (г. Самара, Российская Федераџия)

Аннотация. В данной статье рассматривается проблема формирования экологической культуры у студентов - будущих учителей изобразительного и декоративно-прикладного искусства. Обосновывается необходимость культурологического подхода, который позволяет интегрировать разные отрасли духовной культуры, расширить кругозор учащихся, дать им новые знания, сформировать целостную картину мира. В статье подчёркивается, что экологическая культура проявляется в системе духовных ценностей, во всех видах и результатах человеческой деятельности, связанных с познанием и преобразованием природы. Отсюда напрашивается вывод о необходимости такой профессиональной подготовки учителей, которые, независимо от специальности, смогут осуществлять работу с учащимися по формированию у них экологической культуры. Квалификационная характеристика учителя должна предусматривать его профессиональную готовность осуществлять экологическое обучение и воспитание. Достигнуть необходимого уровня экологической подготовки можно лишь при условии корректировки и обновления существующих образовательных программ. В статье предложена модель формирования экологической культуры средствами изобразительного искусства, определено содержание, условия и этапы её реализации. Представленная модель является трёхуровневой, и в статье рассматривается каждый из них; обосновываются необходимые организационно-педагогические условия, выделяются методологические подходы (культурологический, историко-краеведческий, личностно-ориентированный, деятельностный) и методологические принципы (научности, систематичности, последовательности, наглядности, направленности обучения, культуросообразности, природосообразности). В заключении статьи подчёркивается, что предложенная модель позволила организовать в педагогическом вузе непрерывный процесс, направленный на формирование экологической культуры у будущих учителей, а реализованный на её основе подход способствует становлению новой парадигмы. Причём уровень экологической культуры будущего педагога будет определяться не только успешностью овладения научными знаниями, но и мировоззренческой и поведенческой позицией, проявляемой в его профессиональной деятельности.

Ключевые слова: экологический кризис; модель; культурологический подход; педагогическое образование; экологическая культура; экология; изобразительное искусство; культура; воспитание; краеведение; музейная практика; организационно-педагогические условия; парадигма; интеграция; постнеклассическая картина мира. 
В наше время для большинства стран экологические проблемы стали приобретать первостепенное значение. Замечательный русский писатель Валентин Распутин писал: «Экология стала самым громким словом на земле, громче войны и стихии». Экологическая ситуация на планете стала отличаться противоречивостью, остротой и постоянно нарастающими масштабами проявления. Так как сложность и серьёзность ситуации определяется не только ухудшением состояния природной среды, но и кризисом самого человека, проблемы экологии становятся областью пристального внимания специалистов разных областей [1, с. 42-43]. Именно поэтому очевидно важной является необходимость формирование личности, направленной на правильное, гармоничное взаимодействие с биосферой. Формирование в сознании учащихся целостной картины мира в рамках единой духовной культуры, развитие творческого стиля мышления и деятельности - важнейшая задача школы XXI века. Решение этой задачи реально только в том случае, если будут найдены новые подходы в экологическом образовании, вскрыты и в полной мере изучены законы многочисленных взаимосвязей в природе. В научном наследии В.И. Вернадского, идеи которого значительно опередили своё время, теоретические вопросы экологии были представлены как процесс совместного развития, коэволюции общества и биосферы. Разделяя точку зрения В.И. Вернадского и его ученика Пьера Тейяра де Шардена, можно утверждать, что экология как наука переросла биологические рамки и стала научным знанием о человеке, преобразующем природу и при этом взаимодействующем с ней.

Об этом идёт речь во многих современных законодательных актах: в Законе Российской Федерации «Об охране окружающей среды» (2002 г.); в Постановлении Российской Федерации № 1208 «О мерах по улучшению экологического образования населения»; в Национальной стратегии экологического образования РФ (2000 г.). Однако такой значимый проект Федерального закона, как Федеральный закон № 90060840-3 «Об экологической культуре», не нашёл должной поддержки и в 2005 году был отклонён.

Вызывает большую тревогу и сама учебная дисциплина «Экология». В 1994 году предмет был введён в Федеральный компонент и базисный учебный план государственного образовательного стандарта, а в 1998 году привнесён в (школьный) региональный компонент образования. Этот факт, конечно, негативно сказывается на развитии экологического образования в средней школе. Но ещё сложнее обстоит дело в высшей школе. В учебные планы вместо отдельной учебной дисциплины «Экология» был введён предмет «Биология с основами экологии», причём в качестве факультатива. В силу этого уровень экологической подготовки студентов в вузах оказывается недостаточным и не позволяет им грамотно решать профессиональные и жизненные задачи экологической направленности. Кроме того, очевидно, что современная культура, отдающая предпочтение материальным запросам, практически полностью исчерпала все свои возможности и окончательно привела к нарушению хрупкого равновесия между биосферой и человечеством. В этой связи достижение необходимого уровня экологической подготовки одна из главных задач современной образовательной системы. Возможно ли преодоление сложившейся ситуации и решение поставленной задачи?

В рамках современной постнеклассической научной картины мира решение проблемы возможно посредством формирования у учащихся экологической культуры. С точки зрения культурологии экологическая культура представляет собой раздел духовной культуры, включающей в себя соответствующие знания, традиции, ценностные установки и т.д. По мнению Б.Т. Лихачёва, экологическая культура может рассматриваться как органическое единство экологически развитого сознания, эмоционально-психических состояний и научно обоснованной практической деятельности. Экологическая культура неразрывно связана с сущностью личности в целом, с её различными чертами. Например, философская культура даёт возможность человеку осмыслить и понять назначение человека как продукта природы и общества; политическая - позволяет обеспечивать экологическое равновесие между хозяйственной деятельностью людей и состоянием природы; правовая удерживает человека в рамках разрешённых законами взаимодействий с природой; эстетическая - создаёт условия для эмоционального восприятия красоты и гармонии в природе; физическая - ориентирует человека на эффективное развитие его природных сущностных сил; нравственная - одухотворяет отношение личности к природе и т.д. Взаимодействие всех этих культур и порождает экологическую культуру. Понятие «экологическая культура» охватывает такую культуру, которая способствует сохранению и развитию системы «общество-природа» $[2$, c. 11-13]. Изучению процесса формирования экологической культуры будущих педагогов посвящён ряд публикаций и диссертационных работ. Однако не все аспекты этой проблемы рассмотрены в достаточной мере. Необходимо подчеркнуть, что вопрос экологического обучения и воспитания очень сложен и неоднозначен в толковании, но, несмотря на трудности, это важнейшая задача педагогики.

А теперь несколько слов о таком понятии, как «экологическая культура». Определений этого понятия достаточно много. Так, С.Н. Глазачев рассматривает экологическую культуру как органическую, неотъемлемую часть культуры, которая отражается в мышлении и деятельности человека в отношении окружающей его природы [3]. Выделяя самые важные составляющие экологической культуры, можно обобщить, что это неотъемлемый компонент духовного мира личности, который представляет собой экологически ориентированное сознание и поведение. Анализ понятия «экологическая культура» показывает, что оно включает в себя такие составляющие, как экологические убеждения, экологическая деятельность, экологическое сознание, экологическое самосознание, экологическое мировоззрение, идеал взаимоотношений человека с природой. Академик Н.Н. Моисеев подчёркивал, что формирование экологической культуры личности должно стать непременной частью деятельности всей системы образования $[4$, с. 55-56]. И в стенах учебного заведения будущий учитель должен получить знания об основах теории формирования и развития личности, о проблеме её гармоничного развития. Ведь чтобы всесторонне развивать человека, надо всесторонне его знать. 
В деле подготовки учителя важность приобретают проблема нравственной ориентации профессиональных знаний. Не следует забывать, что учитель формирует не знания в человеке, а человека, обладающего знаниями. Учитель всегда имеет дело с формирующейся личностью. Конечно, профессиональные навыки важны в любом деле, но в экологическом образовании не меньшую роль играет воспитание будущих учителей. Серьёзным помощником в воспитании молодёжи является духовная культура и прежде всего - искусство. Другими словами, воздействовать на экологическое сознание учащихся может только учитель, сам являющийся носителем экологической культуры. Отсюда напрашивается вывод, что проблема может быть решена только при условии организации такой профессиональной подготовки учителей, которые, независимо от специальности, смогут осуществлять работу с учащимися по формированию у них экологической культуры.

Экологическое образование всё более осознаётся как новый подход к профессиональной подготовке учителя. Квалификационная характеристика учителя должна предусматривать его профессиональную готовность осуществлять экологическое обучение и воспитание. Так как экологическая культура проявляется в системе духовных иенностей, во всех видах и результатах человеческой деятельности, связанных с познанием и преобразованием природы, то для формирования экологической культуры необходимо наличие целостной культуры, то есть связи науки с другими отраслями знания. Только в этом случае наука всё меньше будет ориентироваться на непрерывный технический прогресс, включая в область своего внимания этические, эстетические и художественные интересы общества. В статье «О научном мировоззрении» В.И. Вернадский отмечает, что «научное мировоззрение развивается в тесном общении и широком взаимодействии с другими сторонами духовной жизни человечества. Отделение научного мировоззрения и науки от одновременно или ранее происходившей деятельности человека в области религии, философии, общественной жизни или искусства невозможно. Все эти проявления человеческой жизни тесно сплетены между собою и могут быть разделены только в воображении» [5, с. 1408 1465]. Из широкого спектра духовной жизни людей В.И. Вернадский выдвигал на первое место искусство. Попытки включения гуманитарных и эстетических элементов в интегрированную модель экологического образования предпринимались педагогами с конца XX столетия. Например, В. Сенкевич, работающий над проблемой интеграции науки и искусства в системе экологического образования, писал: «Произведения искусства ... дают запоминающиеся идеалы, модели исторически меняющегося отношения человека к природе, способствуя формированию не только ценностных, но и нормативных знаний учащихся и, в то же время, помогая им воспринять и прочувствовать мир как единое целое. Такое целостное восприятие возможно только в процессе общения с искусством, которое, будучи интегративным по своей сути, образно отражает действительность» $[6$, c. 21-23]. Действительно, в процессе экологического образования учащихся учебные дисциплины гуманитарно-эстетического направления могут иметь большое значение. Изобразительное искусство, например, даёт возможность раскрыть красоту внутренне- го мира человека для того, чтобы он увидел красоту окружающей действительности и у него появилось желание создавать её самому $[7$, с. $25-27 ; 8$, с. $92-$ 93]. Искусство развивает чувство гармонии, которую мы встречаем в природе в целом, развивает целостное восприятие картины мира. Чудесные произведения природы, так же как и она сама, «собраны» из разнообразных образов и красок и служат источником познания и формирования нравственных чувств. Причём очень важен не просто просмотр картин, но и наблюдение, сравнение, анализ закономерностей, выявление причинно-следственных связей как на полотне художника, так и в самой природе.

В профессиональной подготовке студентов факультета «Изобразительное и декоративно-прикладное искусство», в связи с необходимостью повышения роли экологической составляющей качества образования, большое внимание уделяется поиску путей и средств развития экологической культуры у студентов. Очень важно, чтобы будущие педагоги не только имели основательные экологические знания, но и могли их применить в своём творчестве, в будущей педагогической деятельности. Достигнуть необходимого уровня экологической подготовки можно лишь при условии корректировки и обновления существующих образовательных программ. Именно эти положения и легли в основу рассматриваемой работы. Всестороннее изучение проблемы в педагогической литературе позволило выделить методологические nодходы (культурологический, историкокраеведческий, личностно-ориентированный, деятельностный) и методологические приниииы (научности, систематичности, последовательности, наглядности, направленности обучения, культуросообразности, природосообразности). Они и легли в основу разработанной модели формирования экологической культуры средствами изобразительного искусства, определили содержание, условия и этапы её реализации. Модель включает в себя следующие уровни:

Первый уровень. Экологизация учебных предметов. Например, в программе дисциплине «Естественнонаучная картина мира» был выделен модуль, полностью посвящённый изучению научных основ экологии. Особое внимание уделялось интеграции экологии с другими областями знания: «Физика и экология», «Медицина и экология», «Экономика и экология» и т.д. В качестве методов оценки знаний на этом направлении выступают тестирование и проведение олимпиады среди студентов.

Второй уровень. Введение в учебные планы курсов - факультативов, а также проведение мероприятий, относящихся к внеучебной деятельности и практике. На факультете «Изобразительное и декоративно-прикладное искусство» предложен факультативный курс, позволяющий беспрепятственно осуществлять процесс интеграции науки и искусства - «Искусство и экологическая культура». Знакомство с указанным курсом предполагает как аудиторные занятия, так и музейную практику, которая помогает расширить кругозор студентов, дать им новые знания в области краеведения, ускорить их творческое развитие. Во время практики студенты выполняют разные виды учебной работы: сначала перед каждой экскурсией представляются презентации по новым темам (сообщение на 10-15 минут), затем прослушивание и конспектирование рассказа педагога (экскурсовода), далее выполнение зарисовок и эскизов и 
уже дома (в рамках самостоятельной работы) подготовка их подробного анализа с точки зрения художественной и экологической ценности. Таким образом, такая длительная работа с каждым изучаемым полотном в залах Самарского художественного музея определяет достаточное закрепление пройденного материала [9-10]. Несколько слов необходимо сказать о сути предложенных заданий. Художественный анализ картины - это не музейное инвентарное описание с обозначением всех примет, позволяющее в случае надобности «опознать» исчезнувшую картину. Художник должен творчески подойти к анализу картины, выполнить его систематично, грамотно и последовательно. В анализе необходимо рассказать о том, какое композиционное построение имеет картина, почему художник решил именно в такой цветовой гамме изобразить этот сюжет, свой замысел. Нужно уметь рассказать, какой характер носит произведение, какие чувства оно вызывает, какой поучительный или просветительный сюжет выбрал художник, что он хотел этим образом показать. Также необходимо выразить своё отношение к этому произведению. Экологический анализ картины - это анализ произведения с точки зрения описания природных особенностей, с точки зрения того, какая экологическая проблема может быть поднята при изучении этого полотна. Учащемуся необходимо уловить состояние и таинство природы в момент времени и передать это в своих зарисовках. То есть необходимо задуматься над сюжетом и выявить его проблематику, так как любое художественное произведение, писал Д.С. Лихачёв, является неоценимым документальным свидетельством прошлого [11, с. 33-35]. Методом оценивания в данном случае выступает выполнение исследовательского задания на общую тему «Произведение изобразительного искусства, его экологический потенциал» и его презентация. Как уже отмечалось ранее, будущий педагог должен знать, как донести полученные знания, приобретённые умения и навыки до учащихся. С этой целью проводится конкурс разработок проведения Экологического пленера для учащихся средних общеобразовательных или художественных школ. Учитель должен организовать работу с учащимися таким образом, чтобы показать им, что природа умеет и небольшими средствами достигать великих эффектов [12, с. 120-123].

Третий уровень. В рамках третьего направления для учащихся проводится экскурсия по городу «Видеоэкология урбанизированной среды» $[13$, с. 77-78; 14 , с. $34-35 ; 15$, с. $81-84 ; 16$, с. $37-39 ; 17$, с. $23-24$; 18 , с. $55-57 ; 19$, с. $12-17]$. Студентами представлялся отчёт, в котором они описывают общее впечатление от мероприятия и выделяют фрагменты, который произвели на них наибольшее впечатление.

Необходимо отметить, что успешность внедрения представленной модели будет зависеть от многих факторов, в том числе и от определённых педагогических условий, которые целенаправленно создаются, функционируют и развиваются на глубокой научной основе и позволяют сделать процесс формирования экологической культуры более эффективным. Такими условиями являются: учёт возраста учащихся; учёт интересов и потребностей; единство познавательной и практико-преобразовательной деятельности; непрерывность экологического образования; разнообразие форм, методов и видов работы; органи- зация целенаправленного общения и взаимодействия с природой как особое условие, обеспечивающие формирование экологической культуры человека.

В заключение необходимо отметить, что разработка и внедрение в учебный процесс представленной модели позволили выявить сущностные характеристики экологической культуры будущих педагогов; определить приоритетные направления, по которым будет осуществляться её формирование; осуществить междисциплинарную интеграцию в процессе изучения специального курса «Искусство и экологическая культура»; определить и создать организационно-педагогические условия её эффективного формирования. Предложенная модель позволила организовать в педагогическом вузе непрерывный процесс, направленный на формирование экологической культуры будущих учителей, а реализованный на её основе подход способствует становлению новой парадигмы. Уровень экологической культуры будущего педагога будет определяться не только успешностью овладения научными знаниями, но и его мировоззренческой и поведенческой позицией, проявляемой в профессиональной деятельности.

\section{СПИСОК ЛИТЕРАТУРЫ:}

1. Будыко М.И. Глобальная экология. М.: Мысль, 1977. 328 с.

2. Лихачев Б.Т. Философия воспитания. М.: Владос, $2010.333 \mathrm{c}$.

3. Глазачев С.Н. Экологическая культура учителя: исследования и разработки экогуманитарной парадигмы. М.: Современный писатель, 1998. 432 с.

4. Моисеев Н.Н. Восхождение к Разуму. Лекции по универсальному эволюционизму и его приложениям. М.: Мысль, 1993. 346 с.

5. Вернадский В.И. Научная мысль как планетное явление / отв. ред. А.Л. Яншин. М.: Наука, 1991. 234 с.

6. Сенкевич В.М. Как учить экологии. 3-е изд. М.: Просвещение, 2003. 96 с.

7. Кравченко А.И. Культурология: учебное пособие для вузов. 4-е изд. М.: Академический Проект «Трикста», 2003. 496 с.

8. Соколов Э.В. Культурология: Очерки теорий культуры. М.: Интерпракс, 1994. 269 с.

9. Самарский художественный музей. От модерна до авангарда. Самара: Издательский дом «АГНИ», 2002. $186 \mathrm{c}$.

10. Самарский художественный музей. Наследие. Самара: Ред.-изд. фирма «НИКА», 2004. 211 с.

11. Лихачев Д.С. Русская культура. М.: Искусство, 2000. 440 с.

12. Маркович Д.Ж. Социальная экология. М.: Издво Рос. ун-та дружбы народов, 1997. 435 с.

13. Одум Ю. Экология. М.: Мир, 1986. Т. 1. 328 с.; T. $2.376 \mathrm{c}$.

14. Пономарева И.Н. Общая экология. М.: Вентана-Граф, 2007. 268 с.

15. Федоров В.Д., Гильманов Т.Г. Экология. М.: Устойчивый мир, 2001. 323 с.

16. Чернова Н.М., Былова А.М. Экология. М.: Дрофa, 2004. 416 c.

17. Шварц С.С. Экологические закономерности эволюции. М.: Наука, 1980. 153 с.

18. Шилова Е.И., Банкина Т.А. Основы учения о биосфере. СПб.: Издательство С.-Петербург. университета, 2005. 352 с.

19. Данилов-Данильян В.И. Перед главным вызовом цивилизации. М.: Инфра-М, 2005. 224 с. 


\section{DEVELOPMENT OF ECOLOGICAL CULTURE OF PROSPECTIVE FINE AND DECORATIVE ART TEACHERS}

(C) 2017

Levina Svetlana Viktorovna, candidate of pedagogical sciences, associate professor of Physics, Mathematics and Methods of Teaching Department Samara State University of Social Sciences and Education (Samara, Russian Federation)

Abstract. This paper considers the problem of development of ecological culture of students - prospective teachers of fine and decorative art. The author proves the necessity of culturological approach, which allows to integrate different fields of spiritual culture, to expand students' horizons, to give them new knowledge, to form a coherent picture of the world. The paper emphasizes that ecological culture is manifested in the system of spiritual values, in all the results of human activity related to cognition and transformation of nature. Hence it is necessary to train teachers who will be able to work with students and develop their ecological culture. Qualification characteristics of a teacher should provide his/her professional readiness to implement environmental training and education. To achieve a necessary level of environmental training is possible only by adjusting and updating existing educational programs. The paper contains a model of development of ecological culture through art; it determines the content, terms and stages of its implementation. The model consists of three levels and the paper discusses each of them; the author also describes necessary organizational-pedagogical conditions, methodological approaches (cultural studies, local history, student-centered, activity-based) and methodological principles (of scientific character, systematic character, consistency, clarity, orientation, training, conformity to culture, of natural law). In conclusion, the paper emphasizes that the proposed model allows to organize a continuous process at a pedagogical university that is aimed to develop ecological culture of prospective teachers.

Keywords: ecological crisis; model; culturological approach; teacher education; environmental education; ecology; art; culture; education; local history; museum practice; organizational and pedagogical conditions; paradigm; integration; post-nonclassical picture of world.

УдК 378

Статья поступила в редакцию 22.09.2017

\section{ОРГАНИЗАЦИЯ САМОСТОЯТЕЛЬНОЙ РАБОТЫ СТУДЕНТОВ В РАМКАХ КОМПЕТЕНТНОСТНОГО ПОДХОДА ОБУЧЕНИЯ}

Макаров Сергей Иванович, доктор педагогических наук, профессор, заведующий кафедрой высшей математики и экономико-математических методов Самарский государственный экономический университет (г. Самара, Российская Федерация)

Бунтова Елена Вячеславовна, кандидат педагогических наук, доцент кафедры высшей математики и экономико-математических методов; доцент кафедры физики, математики и информационных технологий Самарский государственный экономический университет (г. Самара, Российская Федерация);

Самарская государственная сельскохозяйственная академия

(2. Кинель, Самарская область, Российская Федерация)

Аннотация. В рамках современной парадигмы целью высшего образования является подготовка компетентного специалиста, владеющего методами самостоятельного пополнения профессиональных знаний. Целью исследования стало изучение и анализ основных принципов компетентностного подхода в образовании, определение места самостоятельной работы студентов в образовательном процессе высшей школы, выявление основных характеристик самостоятельной работы студентов в рамках компетентностного подхода. Исследование научной литературы, касающейся определения самостоятельной работы студентов в рамках компетентностного подхода в образовании, дало возможность осуществить выбор понятия самостоятельной работы, которое наиболее четко отражает основные характеристики данного вида учебной деятельности. Показан дидактический потенциал самостоятельной работы студентов в рамках компетентностного подхода в образовании. В работе указаны основные педагогические условия организация самостоятельной работы студентов на основе компетентностного подхода, которые обеспечивают подготовку студентов к профессиональной деятельности. Анализ научной литературы позволил показать, что эффективной профессиональной подготовке способствует реализация компетентностного подхода к организации самостоятельной работы студентов вузов. Кроме того, определено содержание самостоятельной работы студентов в соответствии с государственными образовательными стандартами. Предложена условная дифференциация студентов по уровням профессиональной обучаемости. Определены организационная, методическая и педагогическая составляющие процесса организации самостоятельной работы студентов в рамках компетентностного подхода.

Ключевые слова: профессиональные компетенции; умения и навыки; компетентность; модульное обучение; проектное обучение; проблемное обучение; самостоятельная работа студента.

Современные социально-экономические условия развития государства требуют от системы высшего образования подготовки конкурентоспособного специалиста, обладающего профессиональными компетенциями современного уровня, стремящегося к самообразованию и способного адаптироваться к но- вациям. Современные требования учтены в Федеральных государственных образовательных стандартах высшего образования через методологию компетентностного подхода $[1 ; 2]$. В связи с чем результаты подготовки выпускников высших школ определены через компетенции. 